\title{
A NOTE ON
}

\section{T R A N S L I T ER A T I O N}

The essays assembled in this volume were written for a variety of purposes and audiences, and they adopt a variety of schemes for transliterating Indic words. We have chosen to respect that diversity; no single system of transliteration is correct for every use. Certain terms are so important, however, that they recur often, and sometimes with different spellings. In the list that follows, we provide a partial list of such terms, hoping it will help readers make connections between one chapter and the next.

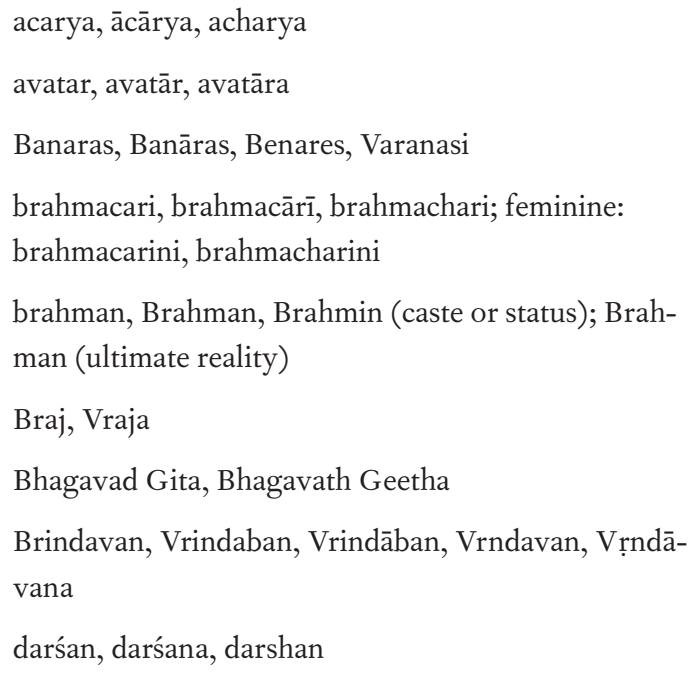


daśahrā, Dassehra, Dussehra

deepa, dīpa, diya

dharm, dharma

Deepavali, Divali, Divālī

Ganapati, Gaṇeśa, Ganesh, Ganesha

Gobardhan, Govardhan

Hara hara Mahadev, hara hara mahādeva

Jamuna, Jamunā, Jumnā, Yamuna

jyot, jyoti

Krishna, Kṛșna

kumkum, kunkum

Lakshmi, Lakshmiji, Lakșmī

Maharajji, Maharaj-ji

Mathura, Mathurā

prasad, prasāda, prashad

Ram, Rām, Rama, Rāma

Ramayan, Ramayana, Rāmāyaṇa

Rāmcaritmānas, Ramcharitmanas

Ramlila, rāmlīlā

rāsa; raas leela, rāsa līlā, rās līlā, ras lila

sadguru, satguru, Satguru

Śaiva, Shaiva

sākta, shakta

śakti, shakti

samskara, saṁskāra, sanskar, saṅskāra

Shudra, sūūdra

Shiva, Siva, Śiva

Sri Vaisnava, Śrī Vaiṣnava

svarup, swarup 
tika, țīkā, teeka

Vaishnava, Vaișṇava

Varanasi. See Banaras.

Venkatesvara, Venkateswara

Vishnu, Viṣṇu

Vraja. See Braj.

vrata, vratam

Vrindaban, etc. See Brindavan. 
This page intentionally left blank 